\title{
XII. Westdeutsche Nachkriegszeit und ihr Buchhandel
}

1945-1949

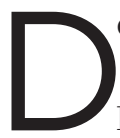

eutschland war im Mai 1945 von amerikanischen, englischen, sowjetischen und einigen französischen Truppen vollständig besetzt. Ein großer Teil der Städte ist durch Luftangriffe weitgehend zerstört gewesen. Dagegen waren diese Angriffe auf die Industrie weniger wirkungsvoll. Allerdings verhinderten die Alliierten zunächst ihre Weiterarbeit. Lediglich die Bauern durften arbeiten wie bisher. Churchill, Roosevelt und Stalin hatten sich auf der Konferenz von Jalta im Februar 1945 auf die Einteilung in vier Besatzungszonen geeinigt, auch auf vier Sektoren in Berlin von Amerikanern, Engländern, Franzosen und Sowjets, außerdem auf die «vier D's»: Demilitarisierung, Demontage, Denazifizierung und Demokratisierung. Über die Reparationen gab es keine allgemeinen konkreten Absprachen. Das sollte nachgeholt werden auf der Konferenz von Potsdam im Juli und August 1945.

Sie wurde kein großer Erfolg, auch nicht im Hinblick auf die Grenze zu Polen. Es ging um große Gebiete, im Wesentlichen um Ostpreußen, Pommern und Schlesien. Man einigte sich auf einen Kompromiss, der später dazu führte, dass Polen den größten Teil dieser Gebiete bis zur Oder und zur Görlitzer Neisse behalten konnte. Er bedeutete, dass die Alliierten in ihren Besatzungszonen Millionen Vertriebene aufnehmen und versorgen mussten. Trotzdem gab es noch eine nicht geringe Einigkeit der Sieger. Das änderte sich erst im nächsten Jahr. 1946 begann der «Kalte Krieg» (Walter Lippmann), als die Westmächte erkannten, dass Stalins Außenpolitik aggressiv auf die Ausdehnung seines Machtbereichs gerichtet war. Nun wurde Deutschland zum zentralen Schauplatz der Auseinandersetzung und trotz seiner Niederlage mit seinen drei westlichen Besatzungszonen zum Schlüssel für die Zukunft Europas und allmählich eine Art Verbündeter der Westalliierten als Bollwerk gegen den Osten. Amerikaner und Engländer gründeten im Dezember 1946 ein vereinigtes Wirtschaftsgebiet, im März 1946 sprach US-Präsident Truman zum ersten Mal davon, dass die Welt sich spalten würde in ein westlich-demokratisches und ein östlich-kommunistisches System. Und mit einer Rede im Juni 1948 kündigte US-Außenminister Marshall ein umfassendes Hilfspro- 
gramm für das notleidende Europa an mit Milliardenunterstützungen auch für Westdeutschland und West-Berlin, den «Marshall-Plan». Dafür fand noch im selben Monat eine Währungsreform statt. Sie brachte die

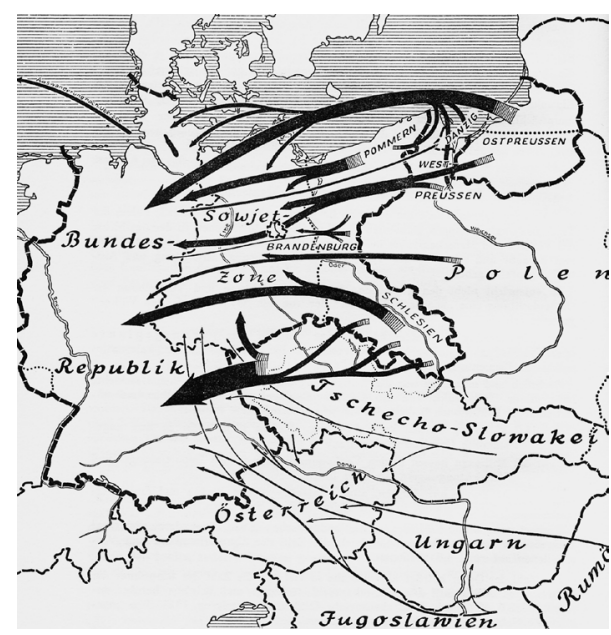

Vertreibungsgebiete nach dem 2. Weltkrieg. neue D-Mark, deren Einführung in WestBerlin von Stalin beantwortet wurde mit der Berlin-Blockade, der Unterbrechung von Landverbindungen zwischen WestBerlin und Westdeutschland. Amerikaner und Engländer überrundeten das mit einer gigantischen «Luftbrücke». Inzwischen hatten die Westalliierten beschlossen, einen westdeutschen Teilstaat gründen zu lassen. Auf ihren Vorschlag begann am 1. September 1948 der Parlamentarische Rat in Bonn seine Beratungen über dessen Verfassung und beschloss am 8. Mai 1949 das Grundgesetz. Vier Tage später hat Stalin die Blockade Berlins beendet.

Die Nachkriegswirtschaft Deutschlands litt zunächst unter einer hohen Inflation. Folge waren Schwarzmarktgeschäfte und Tauschwirtschaft. Größter Verlierer ist die Stadtbevölkerung gewesen. Die Bauern machten gute Geschäfte. Bewirtschaftung von Versorgungsgütern und Preisregulierung halfen da nicht viel weiter. Eine katastrophale Versorgungskrise mit großem Hunger in den Städten begann im Winter 1946/47 und verschärfte sich nach einer Missernte 1946 und einem grausam kalten Winter 1946/47. Deshalb setzten die USA nun auf die Wiederankurbelung der deutschen Wirtschaft, bald Engländer und Franzosen ebenso. Denn ähnlich wie in der Verwaltung gab es letztlich auch in der Wirtschaft keine «Stunde Null». Im Vergleich zur Mitte der dreißiger Jahre war das Anlagevermögen der Industrie sogar immer noch um ungefähr zwanzig Prozent höher, weil das Hitler-Regime es für die Vorbereitung des Krieges durch riesige Investitionen verbessert und während des Kriegs die Steigerung der Produktion durch technische Neuerungen erhöht hatte.

Es fehlten nur die politischen Rahmenbedingungen. Deren Wende kam am Sonntag, 18. Juni 1948, vormittags der erste Teil mit der Währungsreform, der zweite am Nachmittag mit der Ankündigung Ludwig Erhards, dass die Bewirtschaftung von Lebensmitteln und anderen wichtigen Gütern ab Montag aufgehoben werde. Er war Direktor des den Westalliierten 

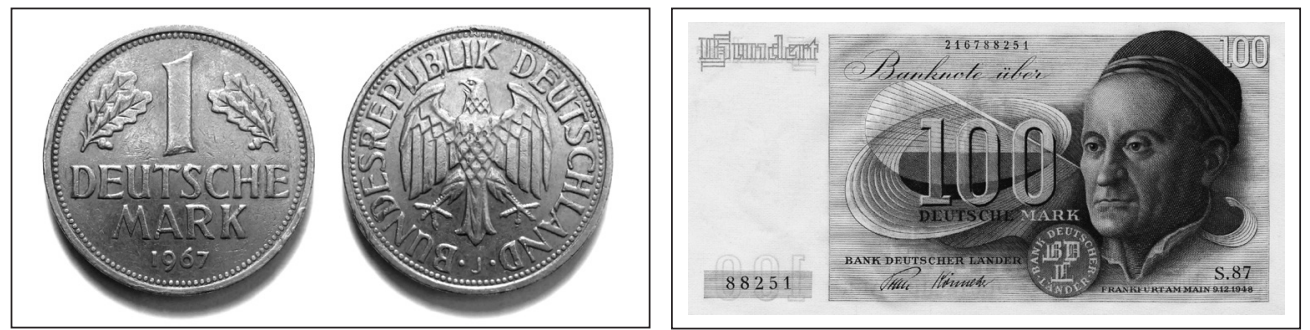

Einführung der Deutschen Mark (DM) 1948

unterstellten Wirtschaftsrats in Frankfurt am Main und hielt diese Rede ohne Absprache mit ihnen. Ein unerhörter Handstreich. Als General Clay ihn zur Rede stellte und fragte, wie er dazu käme, die alliierten Vorschriften zu ändern, war seine Antwort: «Ich habe sie nicht geändert. Ich habe sie aufgehoben.» Aber er hatte Glück. Sein marktwirtschaftlicher Coup brachte der westdeutschen Wirtschaft in Verbindung mit der einsetzenden Hilfe des Marshall-Plans einen ersten Aufschwung und war das Ende der Mangelwirtschaft sowie der erste Schritt zum bald beginnenden «Wirtschaftswunder» der Bundesrepublik, deren erster Wirtschaftsminister er geworden ist.

Die Siegermächte haben sofort nach Kriegsende im Buchmarkt strenge Kontrollen eingeführt, weil Bücher eine wichtige Rolle spielen sollten bei der Entnazifizierung und Demokratisierung. Schon drei Tage nach dem Ende des Kriegs hat General Eisenhower als Oberbefehlshaber der Alliierten am 12. Mai 1945 das Militärregierungsgesetz Nr. 191 erlassen, mit dem das Drucken, Veröffentlichen, Vertreiben und Verkaufen von Zeitungen, Zeitschriften, Büchern und anderen verboten wurde, ergänzt am selben Tag durch die Nachrichtenkontrollvorschrift Nr. 1 (Information Control Regulation No.1). Sie regelte Ausnahmen von diesem Verbot, indem mit schriftlicher Genehmigung der Militärregierung unter bestimmten formalen Bedingungen Lizenzen an natürliche oder juristische Personen gegeben werden konnten. Verstöße gegen beide Vorschriften waren bedroht mit der Verurteilung durch Militärgerichte bis zur Todesstrafe.

Voraussetzungen für eine Lizenz waren in der Praxis eine einwandfreie demokratische Haltung und ausreichende berufliche Kenntnisse. Sie wurde in der US-Zone vergeben von der Information Control Division (ICD), und zwar von einer örtlichen Dienststelle, die das Vorliegen der Voraussetzungen prüfte, dann einen Vorschlag an das Hauptquartier der ICD in Berlin gab, und, wenn dort zugestimmt wurde, die Lizenz erteilte. In München erhielten sie 1945/46 insgesamt 4,1 Buchverlage, zunächst oft kirchliche 
oder solche mit technischen Veröffentlichungen, dann auch literarische Verlagsunternehmen mit oder ohne Sachbüchern. Von den wichtigen Münchener Verlagen erhielten Piper und Carl Hanser schon im Januar 1946 ihre Lizenz, weil Piper sich im «Dritten Reich» in neutrale Unterhaltungsliteratur zurückgezogen hatte und Hanser in dieser Zeit die Literatur aufgab und nur noch technische Literatur veröffentlichte.

Dann wurden Mitte 1946 an ein und demselben Tag, am zo. August, drei wichtige andere Lizenzen erteilt in politischen Problemfällen, und zwar für den Biederstein Verlag, den Verlag von Franz Hanfstaengl und den Leibniz Verlag. Biederstein war problematisch als Nachfolger von C.H.Beck, weil Heinrich Beck 1937 Mitglied der NSDAP geworden ist. Das Problem bei Hanfstaengl war das merkwürdigste, denn sein Eigentümer Ernst («Putzi») Hanfstaengl ist seit 1922 mit Adolf Hitler befreundet gewesen, hatte 1923 den «Marsch auf die Feldherrnhalle» mitgemacht und bald als einziges Mitglied der Münchner Oberschicht geholfen, die Finanzierung der NSDAP zu organisieren. Aber 1937 kam ein Bruch. Joseph Goebbels denunzierte ihn bei Hitler, «Putzi» Hanfstaengl musste nach England fliehen, war dort von den Nationalsozialisten mit dem Tode bedroht und wurde im Krieg politischer Berater von US-Präsident Roosevelt für Deutschland. Deshalb wurde auch sein Fall mit einer Lizenz positiv entschieden. Beim Leibniz Verlag war es ähnlich wie bei Biederstein, nämlich als Nachfolger des Oldenbourg Verlags, dessen Inhaber Alexander Oldenbourg 1943 in die NSDAP eingetreten ist, aus denselben Gründen wie Heinrich Beck, nämlich um den Verlag über die Runden zu bringen.

Für C.H.Beck trat 1946 Gustav End als Statthalter auf, der im «Dritten Reich» unbelastet geblieben war, weil er die von ihm mitgesteuerte Deutsche Buchgemeinschaft von NS-Literatur freigehalten hatte, für den Oldenbourg Verlag dessen Lektor Manfred Schröter, der 1937 als Privatdozent für Philosophie von der Technischen Hochschule München entlassen worden ist, weil er mit einer Jüdin verheiratet war. Aus dem Biederstein Verlag entstand 1949 im Nebeneinander wieder C.H.Beck und der Leibniz Verlag verwandelte sich um dieselbe Zeit in den alten, 1858 gegründeten Rudolf Oldenbourg Verlag. Näheres zu Gustav End S. 189, 207 ff.

Die Produktion der lizensierten Verlage litt in der Regel unter zwei Problemen. Das eine war die meistens knappe Zuteilung von Papier durch die Besatzungsmacht, das andere sind die Druck- und Bindekapazitäten gewesen, die im Westen während des Kriegs sehr viel stärker zerstört worden waren als im östlichen Deutschland. Trotzdem nahm die Buchproduktion seit 1946 ständig zu, denn der Lesehunger der Westdeutschen war 
groß und der Preis der Bücher mit der alten Reichsmark niedrig. Aber dann wurde in den Westzonen am 21. Juni 1948 und drei Tage später in Westberlin mit der Währungsreform die Deutsche Mark eingeführt, die den Lesehunger erheblich zurückdrängte. Nun waren plötzlich lang entbehrte andere Güter auf dem Markt, deren Anschaffung wichtiger wurde als die von Büchern. Das führte zu einer Absatzkrise im Buchhandel. Im Wesentlichen haben sie nur solche Verlage überstanden, die noch ausreichend gute Literatur aus der Zeit vor dem Nationalsozialismus hatten, die «back list», Biederstein/C.H.Beck zum Beispiel mit der «Kulturgeschichte der Neuzeit» von Egon Friedell und besonders mit seiner juristischen Literatur. 
https://doi.org/10.17104/9783406684883-183, am 26.04.2023, 10:57:51 Open Access - (oc) EY - http://www.beck-elibrary.de/agb 